\title{
Telični glagoli i ograničena situacija u kineskom jeziku
}

Xiaolei S. Jin*

Univerzitet u Beogradu, Filološki fakultet, Katedra za orijentalistiku

Ključne reči:

teličnost

ograničenost

rezultativnost

glagol

kineski jezik

srpski jezik

\section{Apstrakt}

Zasnovan na korpusnoj analizi, ovaj rad ispituje kineske telične, odnosno rezultativne glagole i veze koje oni imaju sa ograničenim situacijama. Njegov cilj jeste da empirijskom i kvantitativnom analizom rasvetli distribuciju teličnih glagola u narativnom diskursu, kao i njihove mogućnosti i načine izražavanja ograničenosti bez sadejstva sa drugim aspekatskim operatorima. Rezultati istraživanja ukazuju na neophodnost dalje podele ove glagolske klase na nerezultativne i rezultativne glagole, iz tog razloga što između ove dve podgrupe teličnih glagola u kineskom jeziku postoje bitne razlike u pogledu njihove sintaksičke i diskursne primene u izražavanju ograničenosti. Na kraju, poređenjem ovih glagola u kineskom originalu i njihovih prevodnih ekvivalenata u srpskom jeziku, otkrivaju se glavna sredstva kojima se u srpskom izražavaju značenja „ograničenosti“ i „rezultativnosti“ teličnih glagola kineskog jezika. (примюено: 30. јула 2021; прихваћено: 5. новембра 2021) www.anali.fil.bg.ac.rs

\section{АНАЛИ}




\section{Uvod}

Kao jedno od osnovnih semantičkih obeležja glagola, teličnost je univerzalna karakteristika pomoću koje se može proučavati leksički aspekt glagola, dok se ograničenost u lingvistici podvodi pod semantičku kategoriju. Uopšteno govoreći, reči koje označavaju prostorno-vremensko razgraničenje onoga što je označeno, smatraju se celovitim i ograničenim, dok se reči koje omogućavaju tumačenje onoga što je označeno kao kontinuirano smatraju neograničenim. U proučavanju aspekta, odnosno u relevantnoj literaturi pored termina (a)teličnost ${ }^{1} i$ (ne)ograničenost, ${ }^{2}$ često se sreću i termini (im)perfektivnost ${ }^{3}$, a stanje je još haotičnije kada je reč o njihovim prevodima na kineski jezik. ${ }^{4}$ Deklerk (Declerck, 1989, 2007) predlaže da se pojmovi (a)teličnost, (im)perfektivnost i (ne)ograničenost zasebno vežu za ontološki (tj. leksički), gramatički i aktualizovani (tj. situacioni) aspekt. Drugim rečima, teličnost je distinktivno semantičko značenje glagola ili glagolskih fraza, koje se konceptualizuje kao vrsta aspektualne situacije koja teži prirodnom završetku. Međutim, ovaj prirodni završetak ne poklapa se nužno sa temporalnom završnom tačkom, dok značenje ograničenosti spada u kategoriju pragmatike, koje podrazumeva aktualnu situaciju koja je dostigla temporalnu završnu tačku, bez obzira da li je ta završna tačka prirodna ili ne. ${ }^{5}$

Odnosima između telične i ograničene situacije u kineskom jeziku bavili su se brojni stručnjaci, među kojima su Smit (Smith, 1991/1997), Ću (Chu 1987, cf. Yang 1995), Jang (Yang, 1995), Sijao i Mekeneri (Xiao/McEnery, 2004) i drugi. Smit (1997) je, proučavajući aspekt kineskog jezika, zapazila, između ostalog, da u kineskom jeziku, posebno u diskursu, nisu neuobičajene takve rečenice čiji predikatski glagoli ne poseduju aspekatsko obeležje, i nazvala ih je rečenicom LVM (tj. sentences that lack a viewpoint morpheme). Uzimajući takvu rečenicu s glagolom ostvarenja (XIE GONGZUO BAOGAO/pisati radni izveštaj) sa vremenskom subordiniranom klauzom (when-clause) kao primer za analizu, ona zaključuje da su LVM rečenice „neutralne“ po aspekatskoj vrednosti (neutral viewpoint) jer dopuštaju i „otvoreno“ $i$ „zatvoreno“ tumačenje. Stoga, ona smatra da su LVM rečenice „neutralne“ po pitanju aspekatske vrednosti jer ne mogu da se pokazuju niti kao imperfektivne niti kao perfektivne rečenice (Smith, 1997: 77-81). Međutim, termin neutralni aspekt (neutral viewpoint) ne odnosi se na stativne glagole jer oni ne moraju da budu markirani aspekatskim

1 Pojam teličnost (telic) se kod Vendlera (Vendler, 1967), Dautija (Dowty, 1979), Smit (Smith, 1991/1997) i drugih odnosi na predikatsku situaciju, koju Deklerk (Declerck, 2007) naziva ograničenost. Vendler (1967: 101) za teličnost upotrebljava naziv terminus, i daje sledeću definiciju „(terminus) which is logically necessary to their being what they are“. S druge strane, Smit (Smith, 1991/1997) teličnost shvata kao promenu koja „označava završetak procesa“. Na konceptualnu razliku između ateličnih i teličnih događaja, Dauti (Dowty, 1979) ukazuje različitim logičkim implikacijama, koje on naziva „imperfektivim paradoksom“, što znači da atelična radnja u progresivu implicira istinitost radnje izražene u preteritu ili perfektu.

2 Vidi Declerck, 1989, 2007

3 Vidi Comrie, 1976

4 Na primer, termini telic i perfective se na kineski prevode rečju WANCHENG, koja ima značenje „kompletivnost“ (v. Yang, 2000; Sun, 2006). Pored toga, termini telic i boundedness na kineski jezik se prevode i rečju YOUJIE, koja znači „sa granicom, ograničenost“ (v. Shen, 1995).

5 Detaljnije o tome pogledati kod Deklerka (Declerck, 2007: 54-55). 
obeležjima (Smith, 1997: 278), niti na rezultativne, budući da se ova klasa glagola, prema njoj, ne može pouzdano razlikovati od stativnih zbog morfoloških neodređenosti relevantnih glagolskih konstelacija (Smith, 1997: 81). Dakle, u njenom istraživanju nije utvrđeno da li je situacioni proces LVM rečenice s rezultativnim glagolima ograničen ili ne.

Ću (Chu 1987, cf. Yang 1995) i Jang (Yang, 1995: 138-39) takođe zapažaju da se u diskursu često sreću rečenice kojima nedostaju aspekatski markeri, koje se tumače ili kao imperfektivne, irealne rečenice, ili kao perfektivne rečenice kojima je aspekatsko obeležje izostavljeno zbog određenih diskursnih pravila. Na primer, u nizu događaja, samo je poslednji obeležen aspekatskim markerom, dok ostali obično ostaju neobeleženi, osim ako govornik ne poželi da se neki od njih izdvoji kao zaseban događaj. Dakle, Jang ne smatra takve rečenice neodređenim po aspekatskoj vrednosti. Sijao i Mekeneri (Xiao/McEnery, 2004) kasnije su došli do istog zaključka, oslanjajući se na analizu novinskih tekstova na kineskom jeziku, materijala iz izbalansiranog korpusa engleskog i kineskog jezika, kao i jednosmernog paralelnog korpusa (engleski je izvorni, a kineski ciljni jezik). Na osnovu rezultata istraživanja, oni tvrde da postulat autorke Smit o „aspekatskoj neutralnosti“ LVM rečenica ne odgovara činjeničnom stanju koje vlada u kineskom jeziku. Zapravo, u korpusnim podacima, kako navode, ne nalazi se nijedna LVM rečenica koja „nije ni perfektivna, ni imperfektivna“ (Xiao/McEnery, 2004: 236). Prema njihovom mišljenju, razlog zašto Smit smatra da su LVM rečenice "neutralne“ po aspekatskoj vrednosti leži u tome što je njena analiza bila ograničena na izolovne pojedinačne rečenice, tj. nije obuhvatila širi jezički kontekst, tj. diskurs. Stoga, oni umesto neutralnog aspekta o kome govori Smit predlažu upotrebu koncepta "nulti“ aspekt (the zero aspect), koji se odnosi na rečenice koje opisuju realne, dinamične situacije, ali nisu obeležene aspekatskim obeležjima, i kao takve, u zavisnosti od konteksta, mogu se tumačiti ili kao ograničene ili kao neograničene (2004: 239-40).

Aktivne glagole nemarkirane aspekatskim obeležjima u kineskom jeziku Jahontov (Yahongtuofu, 1958: 94) naziva glagolima opšteg aspekta (YIBANTI). Sličan pojam nalazi se i kod Vanga (PUTONGMAO/opšti lik, v. Wang, 1943/1985: 152) i Džanga (YIBANTI/opšti aspekt ili LINGXINGTAI/nulti aspekt, v. Zhang, 1957), samo što se on odnosi i na stativne i na rezultativne glagole. Opšti aspekt, prema Džangu, u stvari predstavlja semantičku kategoriju i „ne ograničava gramatičko značenje glagola“ (Zhang, 1957: 164).

Problematikom ograničenosti u kineskom jeziku bavili su se i drugi istraživači, među kojima su i Li i Tompson (Li/Thompson, 1981) i Šen (Shen, 1995, 2004). Tvrdeći da je događaj celovit ako je vremenski, prostorno ili koncepcijski ograničen, Li i Tompson (Li/Thompson, 1981: 185-86) izneli su četiri načina na koje se ostvaruje ograničenost događaja, i to: kvantifikovanjem ili određivanjem događaja, pomoću glagola koji je po inherentnom značenju ograničen i diskursnim sredstvima, kao što je biti prvi u događajnom nizu. Međutim, u njihovom proučavanju gorepomenutih ograničenih situacija nije razmatran slučaj u kojem je aspekatski marker odsutan. Dakle, u svim njihovim navedenim primerima prisutan je marker za perfektivnost 
$L E$, te je teško utvrditi da li se ograničenost ostvaruje zapravo zahvaljući pojavljivanju LE u rečenici ili, ipak, ulogama drugih sredstava. Šen (Shen, 1995, 2004) bio je prvi koji je primenio princip „koincidencije kvantifikovanog objekatskog argumenta i ograničenosti situacije“ u kineskoj gramatici. Po njemu, ako je radnja ograničena, onda se objekatski argument tumači kao ograničen, i obrnuto, tj. ako je objekatski argument ograničen, onda se i radnja tumači kao ograničena. Taj princip u kineskom jeziku važi kako za odnose između imenica i glagola, tako i za odnose između imenica i prideva, odnosno, između glagola i modifikatora.

$\mathrm{Na}$ osnovu svega gorenavedenog možemo zaključiti da, iako su do sada već sprovedena obimna istraživanja inherentnih aspektualnih karakteristika kineskih glagola, još uvek nije sveobuhvatno i detaljno proučavana problematika odnosa teličnosti glagola i ograničenosti situacije u kineskom jeziku, odnosno pitanje kako i u kojoj meri ovi glagoli mogu samostalno, tj. bez sadejstva sa drugim gramatičkim aspekatskim sredstvima, izražavati ograničene situacije.

\section{Predmet istraživanja $i$ korpus korišćen pri analizi}

Ovaj rad će se na osnovu korpusne analize pozabaviti gorepomenutom problematikom. Naime, namera nam je da razmotrimo (ne)ograničenost LVM rečenica $u$ narativnom diskursu, uključujući i rezultativne glagole, i to tako što će se poređenjem kineskog originala i prevodnih ekvivalenata u srpskom jeziku porediti (različiti) načini izražavanja ograničenosti u njima.

Polazeći od takve istraživačke namere, a imajući u vidu da dostupni i postojeći korpusi ne zadovoljavaju zahteve našeg istraživanja, bilo je nužno da sami formiramo paralelni korpus kineskog i srpskog jezika (tj. onaj u kome bi kineski bio izvorni, a srpski ciljni jezik), te smo za korpus odabrali osam kratkih priča poznatih savremenih kineskih pisaca koje su istovremeno prevedene na srpski jezik i zvanično objavljene u relevantnim književnim časopisima ili zbirkama u Srbiji. Korpus od osam kineskih priča sastoji se od 77833 karaktera, dok korpus prevoda različitih prevodilaca na srpski jezik ima 265205 znakova.

Vodeći se stavom Kampa i Rajla (Kamp/Rayle, 1993), Hopera (Hopper, 1979, 1982) i drugih, da se u narativnom diskursu ograničenost upravo ogleda u događajnosti, što na aspekatskom planu podrazumeva perfektivnost, kao i postulatom Kampa i Rajla (Kamp/Rayle, 1993) da radnje koje čine događaj moraju biti ograničene da bi se ostvarila temporalna progresija u događajnom nizu, prvo smo uradili segmentaciju tekstova na elementarne diskursne jedinice (EDJ). Segmentacija je urađena prema instrukcijima Teorije retoričke strukture i uputstvu o postupku anotiranja teksta (Mann/Thompson 1988; Carlson/Marcu 2001), ${ }^{6} \mathrm{~s}$ ciljem da se EDJ, prema retoričkim relacijama, razvrstaju na one koje su sa svojom susednom EDJ u relaciji nizanja ili posledice, tj. one koje pripadaju strukturi koja je u narativnom diskursu „istaknuta“ (foregrounded) i utiče na temporalnu progresiju, i one koje su sa svojom susednom EDJ u drugim relacijama (npr. pozadina, elaboracija, tumače- 
nje, itd.), tj. one neograničene koje pripadaju „pozadinskoj“ (backgrounded) strukturi u narativnom diskursu i ne utiču na razvoj narativa u temporalnom planu. Nakon ovih postupaka, dobijeno je ukupno 5825 EDJ u analiziranom korpusu, od kojih je 5423 EDJ sa glagolskim predikatom, 2335 EDJ pripada temporalnoj strukturi teksta (TP EDJ), a 3490 EDJ netemporalnoj strukturi teksta (NTP EDJ).

Zatim smo izdvojili EDJ čije jezgro predikacije čine sam glagol sa eventualnim objektom, a ne i drugi aspekatski markeri ili glagolske dopune faznog značenja. $\mathrm{Na}$ osnovu definicije o opštom aspektu koji je odredio Džang (Zhang, 1957), takve EDJ nazivamo EDJ s glagolima opšteg aspekta (u daljem tekstu: EDJ ${ }_{\text {OP̌̌. AsP. }}$ ), koji broje 2773, što čini oko 47,62\% ukupnog broja EDJ. Poslednji postupak obrade korpusnih podataka urađen je prema glagolskoj klasifikaciji primenjenoj u ovom radu (o tome će biti više reči u daljem tekstu), što je podrazumevalo anotiranje vrste glavih

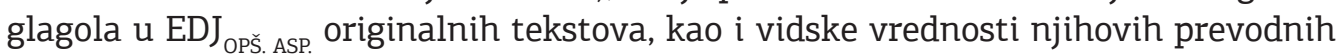
ekvivalenata u srpskom jeziku. Ove EDJ sa anotiranim glagolima kineskog i srpskog jezika čine uzorke naše analize.

\section{Klasifikacija glagola i njihove definicije}

Vendlerova tipologija (Vendler, 1967), zasnovana na distinktivnim semantičkim obeležjima [+/-statičnost], [+/-trajnost] i [+/-teličnost], na osnovu kojih se glagoli dele na glagole aktivnosti, ostvarenja, dostignuća i stanja, ${ }^{7}$ odlikuje se jezičkom univerzalnošću i svakako predstavlja jednu od najprihvaćenijih klasifikacija glagolskih situacija. Pored sistema sa četiri podele glagola, veoma uticajnu tipologiju predstavlja sistem sa pet podela autorki Smit (Smith, 1991/1997) i Jang i dr. (Yang et al., 2009), samo što su se u njihovom slučaju primenjivala različita distinktivna semantička obeležja, a različito su definisane i glagolske klase. Jang i dr. (Yang et al., 2009) smatraju da se telični glagoli u kineskom jeziku mogu podeliti na one čiji proces ne obuhvata segment ostvarenja cilja, (drugim rečima, cilj je, pre svega, potencijalna mogućnost) i one čiji proces nužno obuhvata rezultat jer u protivnom ta radnja uopšte i ne bi bila ta radnja. Stoga su ponudili klasifikaciju zasnovanu na semantičkim obeležjima [+/-dinamičnost], [+/- teličnost] i [+/-rezultativnost] koja sadrži pet klasa, i to glagole: stanja, aktivnosti, semelfaktivnosti, ${ }^{8}$ telične glagole koji u sebi nemaju semu rezultata i telične glagole koji u sebi sadrže semu rezultata, tj. glagole rezultativnosti. Štaviše, na osnovu stepena dinamičnosti i određenosti cilja, oni dalje dele glagole na deset podgrupa, kao što su grupe jače i slabije dinamične

7 Na osnovu Vendlerovog (1967) određenja, glagoli aktivnosti opisuju radnje koje nemaju prirodnu završnu tačku, kao što je to u engleskom slučaj s glagolima run, walk, swim itd. Glagoli ostvarenja opisuju radnje koje imaju proces i prirodnu tačku završetka, kao na pr. one koje se pojavljuju u engleskim izrazima paint a picture, draw a circle, write a letter, itd. Glagoli dostignuća opisuju radnje koje poseduju prirodnu tačku završetka, ali nemaju trajnost, kao što je to slučaj u primerima reach the pot, recognize, find, lose, win, itd. Glagoli stanja opisuju statična stanja kao što su: know, love, be tall, own, itd. Prevodi naziva ovih tipova glagola preuzeti su od Novakova (Novakov, 2005).

8 Ova glagolska klasa po datoj definiciji ista je kao ona u petočlanoj klasifikaciji koju daje Smit. Dakle, Smit (Smith, 1991/1997) na osnovu semantičkih obeležja [+/-dinamičnost], [+/-trajnost], [+/-teličnost] klasifikuje tip glagolske situacije u kineskom jeziku na pet vrsta: stanja, aktivnosti, ostvarenja, dostignuća, semelfaktivnosti. 
aktivnosti, odnosno, grupe teličnih glagola s „jasnim“ i „nejasnim“ ciljem. Osim toga, Jang i dr. takođe su iscrpno anotirali glagole koji su uvršćeni u Rečnik upotrebe glagola kineskog jezika (Hanyu dongci yongfa cidian), koji je priredio C. Meng sa saradnicima (1999), što za nas predstavlja dragocene referentne izvore.

Oslanjajući se na klasifikaciju koju daju Jang i dr. (Yang et al., 2009), [+dinamičnost], [+teličnost] i [+rezultativnost] uzeli smo kao markirana obeležja koja služe za klasifikovanje glagolskog opšteg aspekta. S druge strane, imajući u vidu da u kineskom jeziku nema puno semelfaktivnih glagola, ${ }^{9}$ te da se i oni koji postoje $u$ narativnom diskursu najčešće javljaju u obliku udvojenog glagola (npr. DIAN-DIAN TOU, tj. klimati glavom) ili uz neki aspekatski marker (npr. DIAN LE DIAN TOU, tj. klimnuo/-la je glavom), inače slučajevi koji nisu predmet ovog istraživanja, ovu klasu smo zanemarili. One koji samostalno formiraju predikat EDJ, ako takvih uopšte i ima u korpusu, prema njihovoj semantičkoj osobini [+ aktivnosti] [- teličnosti], uvrstili bismo u klasu glagola aktivnosti.

Stoga smo, u cilju ovog istraživanja, kineske glagole podelili na glagole stanja, aktivnosti, kao i nerezultativne i rezultativne telične glagole. U takvoj klasifikaciji, markiranim obeležjem [+ dinamičnost] razdvajaju se stativni i aktivni glagoli; obeležjem [+ teličnost] razdvajaju se atelični i telični, a obeležjem [+ rezultativnost] razlikuju se oni telični glagoli koji u svojoj semantici ne poseduju semu [rezultata] kao i oni kojima je rezultativnost imanentno značenje. Ove četiri klase glagola i njihove semantičke osobine predstavljene su u sledećoj tabeli:

\begin{tabular}{|l|c|c|c|}
\hline & dinamičnost & teličmost & rezultatixnost \\
\hline GL. STANJA & $\varnothing$ & $\varnothing$ & $\varnothing$ \\
\hline GL. AKTIVNOSTI & + & $\varnothing$ & $\varnothing$ \\
\hline NEREZ. TEL. GL. & + & + & $\varnothing$ \\
\hline REZ. TEL. GL. & + & + & + \\
\hline
\end{tabular}

Napomena: oznaka Ø u tabeli označava da dotična klasa glagola ne poseduje određenu semu.

Tabela 1. Semantičke odlike četiri glagolske klase u kineskom jeziku

Nerezultativni telični glagoli, kao što su: ZUO/raditi, spremati, CHUAN/oblačiti se, ZHUAN/okretati se, XIE/pisati i drugi, s jedne strane, poput glagola aktivnosti, opisuju dinamičan proces, a ipak se razlikuju od glagola aktivnosti po tome što poseduju inherentnu krajnju tačku i stoga su nehomogeni. Dakle, iako su ovi telični glagoli trajni, njihovi subintervali međusobno se razlikuju, zato što su praćeni mogućom promenom stanja. Da bi se potencijalni rezultat ovih glagola ostvario, njima je potrebno uspostaviti spoljašnju materijalnu granicu. S druge strane, u određenom kontekstu, doduše, proces nerezultativnih teličnih glagola može biti prekinut, i to $u$

9 Jang i dr. (Yang et al., 2009) ukupno su anotirali četrnaest glagolskih leksema semelfaktivnosti u Rečniku upotrebe glagola kineskog jezika (Meng et al., 1999). 
bilo kojoj tački razvojnog toka, a tačka prekida (terminalna krajnja tačka) ne mora biti inherentna krajnja tačka (materijalna krajnja tačka), ${ }^{10}$ što je ilustrovano sledećim primerima s glagolom ZUO/raditi, pripremati.

1a) ...(ta) jiu manglu-zhe gei erzi zuo NEREZ. TEL. $_{\text {. }}$ conghua jidan youbing.

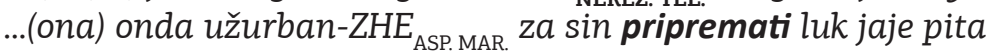

...a onda, užurbano počela (je) da mu priprema ${ }_{\mathrm{Nsv}}$ pitu s lukom $i$ jajima.

(Mo, 2015: 252)

b) Na bu shi mei ge ren dou neng zuo-dao de.

ono ne biti svaki KLAS. za osobe čovek sve moći raditi-stići $i_{\mathrm{REZ} \text {. DOP. }} D E_{\mathrm{MOD} \text {. REČ. }}$

Retko ko bi to uradio.

(Лу, 2015: 88)

Radnja u primeru (1a) ZUO YOUBING/pripremati pitu predstavlja teličnu situaciju koja teži prirodnoj završnoj tački, tj. trenutku kada se pita ispeče. Međutim, radnja u toku trajanja može biti prekinuta u izvesnom trenutku zbog nekog spoljašnjeg faktora (na primer, gašenja šporeta ili zato što vršilac radnje ona ima neke druge obaveze zbog kojih prekida tu radnju, itd.). U ovom slučaju, istinitost same radnje ZUO YOUBING ne zavisi od toga da li će prirodna krajnja tačka biti postignuta ili ne. Prevod na srpski jezik pomoću faznog glagola početi i nesvršenog glagola pripremati ukazuje na situaciju koja ima početnu tačku, a rezultat radnje u datom trenutku još nije ostvaren. Primer (1b) upravo pokazuje da se potencijalni rezultat nerezultativnog teličnog glagola $Z U O$, označen rezultativnom dopunom DAO/stići, pak može poništiti negacijom BU/ne.

Rezultativni glagoli u kineskom jeziku jesu: DIU/(iz)gubiti, WANG/zaboraviti, zaboravljati, YING/pobediti, pobeđivati, DAO/stići, stizati, FAXIAN/otkri(va)ti, JIESHU/završiti, završavati i drugi. Ukoliko bi rezultativnim glagolima nedostajao rezultat, istinitost radnje bi se dovela u pitanje. Na primer, ako glagolu YING/ pobediti, pobeđivati nedostaje rezultat „pobeda“, to više ne bi bila ta radnja. Razliku između ove dve podvrste teličnih glagola mogu lepo ilustrovati primeri sa glagolima QUANSHUO/nagovarati, ubeđivati i SHUOFU/nagovoriti:

2a) Wo quanshuo-le ta mintian bie lai le. ${ }^{11}$

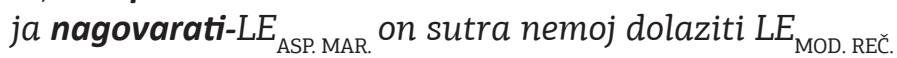
Ja sam ga nagovarao da sutra ne dođe.

b) Wo shuofu-le ta mintian bie lai le. ja nagovoriti- $L E_{\text {ASP. MAR. }}$ on sutra nemoj dolaziti $L E_{\text {MOD. REČ }}$ Ja sam ga nagovorio da sutra ne dođe.

100 pojmu „materijalna tačka“ vidi Lindstedt (1995), koji je postavio koncepte material bound i temporal bound. Slične ideje zastupao je i Bondarko (1987: 46ff, citiran prema Lindstedt, 1995), koji je koristio koncepte internal bound i external bound.

11 Autorkini primeri. Svi primeri u daljem tekstu za koje nisu označeni izvori iz korpusa takođe su autorkini primeri. 
Telični glagol QUANSHUO/nagovarati u primeru (2a) je nerezultativan, dok je glagol SHUOFU/nagovoriti u primeru (2b) rezultativan. Ovde se jasno vidi da situacija prikazana u primeru (2a) ne podrazumeva onu u primeru ( $2 b$ ), iako su obe situacije ograničene, tj. poseduju terminalnu krajnju tačku označenu aspekatskim markerom za perfektivnost $L E$, s tim što proces glagola QUANSHUO/nagovarati ne poseduje materijalnu krajnju tačku - rezultat, koji sadrži proces glagola SHUOFU/ nagovoriti.

Pošto se u kineskom jeziku glagoli iz klase aktivnosti i glagoli dveju podvrsta teličnosti na sintaksičkom nivou različito manifestuju, postoje jezički testovi za klasifikovanje ovih glagola. ${ }^{12} \mathrm{Na}$ primer, testom "glagol + kvantifikovan direktni objekat" može se proveriti da li glagolski proces poseduje inherentnu krajnju tačku, pa se tako glagoli aktivnosti mogu razlikovati od nerezultativno-teličnih. Primera radi, obe date situacije KAI CHE (gl. AKT.: KAI/voziti + OBJ.: CHE/kola, tj. voziti kola) i KAI YI LIANG CHE (gl. AKT.: KAI/voziti + KVAN.: YI LIANG/jedan + KLAS. za vozila + OBJ.: CHE/kola, tj. voziti (jedna) kola) su neograničene jer glagol KAI (CHE)/voziti pripada klasi aktivnosti, te kvantifikator YI LIANG/jedna (kola) ne menja tip situacije; dok su za nerezutativni telični glagol XIE/pisati situacije s kvantifikovanim i nekvantifikovanim direktnim objektom različite po ograničenosti. Naime, glagolska situacija XIE XIN (gl. NEREZ. TEL.: XIE/pisati + OBJ.: XIN/ pisma, tj. pisati pisma) je neograničena, dok XIE SAN FENG XIN (gl. NEREZ. TEL.: XIE/pisati + KVAN.: SAN FENG/tri + KLAS. za pisma + OBJ.: XIN/pisma, tj. pisati tri pisma) ograničena, što znači da kvantifikator SAN FENG/tri (pisma) menja tip glagolske situacije.

Testom „gl. + rezultativna dopuna“ sa potvrdnim ili odričnim značenjem mogu se testirati glagoli čiji procesi (ne) poseduju segment ostvarenja cilja, čime bi se razdvojile dve podvrste teličnih glagola. Tačnije, telični glagoli koji mogu stajati uz rezultativnu dopunu su nerezutativni, npr. HUA WAN HUA (gl. NEREZ. TEL.: HUA/ crtati + REZ. DOP.: WAN/završiti + OBJ.: HUA/crtež, tj. nacrtati crtež); dok nasuprot njima stoje rezutativni glagoli. Ovaj test, u suštini, odražava princip jezičke ekonomičnosti jer rezutativni glagoli, npr. YING/pobediti, u sebi već nose semu rezultata koja je kodirana u semantiku glagolske lekseme, tako da bi njima bilo suvišno dodati još i rezultativnu dopunu, kao spoljašnju krajnju tačku. Na primer, iskaz *YING WAN BISAI (gl. REZ. TEL: YING/dobiti + REZ. DOP.: WAN/završiti + OBJ.: utakmica, tj. *dobiti i završiti utakmicu) je gramatički neispravan. Postoje i drugi jezički testovi kojima se mogu razdvojiti rezultativni od ostalih teličnih glagola. ${ }^{13} \mathrm{Na}$ primer, aspekatski marker za progresivnost ZAI, koji označava da je neki proces u toku (u prevodu: upravo, sada), može stajati uz nerezultativne telične glagole ali ne i uz rezultativne. Uporediti: 
3a) Ta zai hua NEREZ. TEL. yi fu $\mathbf{~ u V A N . ~}_{\text {. }}$ hua.

on $Z A I_{\text {ASP. MAR. }}$ slikati jedan KLAS. za crteže crtež

On upravo (sada) crta neki crtež.

b) *Tamen zai ying REZ. TEL $^{\text {na chang }}{ }_{\text {KVAN. }}$ qiu.

oni $Z_{A} I_{\text {ASP. MAR. }}$ dobiti onaj KLAS. za utakmice fudbalska utakmica

*Oni sada dobijaju utakmicu.

Primer (3a) ilustruje situaciju u kojoj se trajna radnja HUA/crtati odigrava upravo u trenutku govora, a koja će se nakon izvesnog vremena okončati, pri čemu aspekatski marker za progresivnost ZAI označava da je to trajanje u toku. S druge strane, u primeru (3b) rezultat radnje YING/dobiti (utakmicu) ostvaruje se u trenutku, što znači da propozicija dobiti utakmicu nije istinita pre te krajnje tačke, pa se ne može označiti aspekatskim markerom za progresivnost ZAI.

Neki rezultativni glagoli ipak poseduju izvesno trajanje, a taj trajni segment $u$ procesu, po R. Deklerku (Declerck, 2007), predstavlja „pripremni period“ za konačno ostvarivanje cilja. Dakle, procesi koje opisuju glagoli ove podvrste, kao što su: WANGJI/zaboraviti, zaboravljati i FAXIAN/otkri(va)ti, ne svode se na jednu tačku, iako je njihova kritična promena viđena kao trenutna. U značenju ovih glagolskih leksema lako je uočiti tzv. „pripremni period“ za ostvarenje konačnog cilja, samo što se ovo trajanje „pripreme“ u jeziku ne izražava pomoću aspekatskih operatora ZAI i ZHE (odn. obeležjima za progresivnost i durativnost), već leksičkim sredstvima, kao što su prilozi sa značenjem trajanja: JIANJIAN/vremenom, ZHUJIAN/postepeno, MANMAN/lagano, itd. Uporediti:

4) Ta jianjian wangji $i_{\mathrm{REZ} \text {. TEL. }}$-le ziji de shenti...

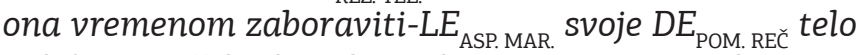

Polako je počela da zaboravlja na sopstveno telo, ...

(Mo, 2015: 249)

Na osnovu gorenavedenih primera, možemo utvrditi da postoje bitne razlike $u$ sintaksičkom ponašanju nerezultativnih i rezultativnih teličnih glagola u kineskom jeziku, što bi moglo da utiče na njihove načine izražavanja ograničene situacije u narativnom tekstu.

\section{Distribucija teličnih glagola opšteg aspekta u korpusu $i$ načini njihovog izražavanja ograničenosti} kursu

4.1. Kvantitativna distribucija EDJ ${ }_{\text {OPŠ. ASP. }}$ s teličnim glagolima u narativnom dis-

Rezultati naše korpusne analize poklapaju se s rezultatima istraživanja Sijaoa i Mekenerija (Xiao/McEnery, 2004) jer u korpusu ne postoji ni jedna EDJ ${ }_{\text {OPš. AsP. }}$ čija je aspekatska vrednost neodređena, kao što to Smit tvrdi. Prema podacima prezento- 
vanim u Tabeli 2, sve EDJ ${ }_{\text {OPŠ. ASP }}$ mogu da se uvrste ili u pozadinsku strukturu narativnog teksta (NTP), ili u strukturu u kojoj se ostvaruje temporalna progresija (TP). Dakle, situacije koje izražavaju ove EDJ u narativnom diskursu, su ili neograničene ili su ograničene, u zavisnosti od konteksta.

\begin{tabular}{|c|c|c|c|c|}
\hline & & EDJOPS. ASP & ATELIČNI & TELIČNI \\
\hline \multirow{2}{*}{$\begin{array}{c}\text { NTP } \\
\text { (struktura pozadine) }\end{array}$} & br. & 2008 & 1795 & 213 \\
\cline { 2 - 5 } & $\%$ & $\mathbf{7 2 , 4 1}$ & $\mathbf{7 9 , 7 8}$ & $\mathbf{4 0 , 7 3}$ \\
\hline \multirow{2}{*}{$\begin{array}{c}\text { TP } \\
\text { (struktura istaknutosti) }\end{array}$} & br. & 765 & 455 & 310 \\
\cline { 2 - 5 } & $\%$ & $\mathbf{2 7 , 5 9}$ & $\mathbf{2 0 , 2 2}$ & $\mathbf{5 9 , 2 7}$ \\
\hline
\end{tabular}

Tabela 2. Relativna distribucija ateličnih i teličnih glagola opšteg aspekta u analiziranom korpusu

\begin{tabular}{|c|c|c|c|c|c|c|}
\hline & & EDJ $_{\text {OPS. ASP. }}$ & STA. & AKT. & NEREZ. TEL. & REZ. TEL. \\
\hline \multirow{2}{*}{$\begin{array}{c}\text { NTP } \\
\text { (struktura pozadine) }\end{array}$} & br. & 2008 & 1332 & 463 & 86 & 127 \\
\cline { 2 - 7 } & $\%$ & $\mathbf{7 2 , 4 1}$ & $\mathbf{9 8 , 1 6}$ & $\mathbf{5 1 , 8 5}$ & $\mathbf{3 2 , 9 5}$ & $\mathbf{4 8 , 4 7}$ \\
\hline \multirow{2}{*}{$\begin{array}{c}\text { TP } \\
\text { (struktura istaknutosti) }\end{array}$} & br. & 765 & 25 & 430 & 175 & 135 \\
\cline { 2 - 7 } & $\%$ & $\mathbf{2 7 , 5 9}$ & $\mathbf{1 , 8 4}$ & $\mathbf{4 8 , 1 5}$ & $\mathbf{6 7 , 0 5}$ & $\mathbf{5 1 , 5 3}$ \\
\hline
\end{tabular}

Tabela 3. Relativna distribucija četiri klase glagola opšteg aspekta u analiziranom korpusu

Prema podacima prikazanim u Tabelama 2 i 3, jasno se vidi tendencija da se EDJ $_{\text {OPŠ. ASP. }}$ češće javljaju u NTP EDJ (72,41\%), a naročito one sa ateličnim glagolima (79,78\%). Međutim, EDJ ${ }_{\text {OPš. ASP. }}$ s teličnim glagolima ipak pokazuju tendenciju češćeg javljanja u TP narativnog diskursa. Tačnije, oko 59,27\% takvih EDJ javlja se u TP, od kojih su nerezultativni telični glagoli OPŠ. ASP. s procentom od 67,05\%, u odnosu na rezultativne telične glagole, čiji procenat iznosi 51,53\%, još konkuretnije za izražavanje ograničenosti u narativnom diskursu.

\subsection{Načini izražavanja ograničenosti teličnih glagola opšteg aspekta}

4.2.1. Načini izražavanja ograničenosti nerezultativnih teličnih glagola opšteg aspekta

Budući da nerezultativni telični glagoli označavaju procese koji su usmereni na cilj, a da pritom sami procesi ne moraju da sadrže segment cilja, načini izražavanja ograničenosti takvih glagola opšteg aspekta u diskursu veoma su slični dinamičnim aktivnim glagolima. Dakle, neophodna su leksička, sintaksička ili diskursna sredstva kojima bi se ostvario potencijalni cilj, ili makar označila terminativna tačka glagolskog procesa. Drugim rečima, ograničenost situacije koju samostalno opisuju ovi glagoli jeste „uslovljena“. U daljem tekstu ćemo primerima pokazati najčešća sredstva primenjena u korpusu kojima ove EDJ izražavaju ograničenost. 


\subsubsection{Kvantifikacija direktnog objekta}

Pogledajmo prvo sledeće primere:

5) Jiezhe, na ren you bihua NEREZ. TEL. $_{\text {yi zhong }}$ KVAN. $y$ yuanyuan de guozi, xiangzhengxing de fang-dao chunbian ...

Zatim, ono čovek opet pokazivati jedan vrsta okrugao $D E_{\mathrm{POM} . \mathrm{REČC}}$ Voće, simboličan $D E_{\text {POM. REČ. }}$ prinositi-stići $i_{\text {REZ. DOP. }}$ usta

Rus je zatim znakovima pokazao ${ }_{\text {sv }}$ okruglu voćku koju je simbolično prineo ustima... (Чи, 2014: 56)

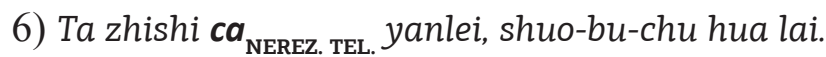

Ona samo brisati suza, govoriti-BU $U_{\mathrm{NEG}}$-izaći $i_{\mathrm{REZ} \text {. DoP. }}$ reč doći $i_{\mathrm{REZ} \text {. DOP. }}$

Ona je samo brisala ${ }_{\mathrm{Nsv}}$ suze, nesposobna da bilo šta kaže.

(Mo, 2015: 253)

U primeru (5) nalazi se kvantifikator YI ZHONG/(jedna) vrsta, koji čini objekat GUOZI/voće kvantitativno određenim, pri čemu je radnji koju opisuje nerezultativni telični glagol BIHUA/pokazivati dodeljena završna tačka, a rečenica dobija perfektivno tumačenje, tj. postaje ograničena. U primeru (6), objekat YANLEI/suza nije određen kvantifikatorom, pa stoga radnja CA/brisati takođe nije kvantitativno ograničena, te je situacija koju opisuje ova EDJ neograničena i predstavlja pozadinsku informaciju glavnog događaja. Ponekad atribut takođe može činiti objekat određenim, pri čemu radnja dobija ograničeno tumačenje, što je ilustrovano sledećem primerom:

7) Jiezhe shoushi ${ }_{\text {NEREZ. TEL. }}$ zhuo shang de wan kuai.

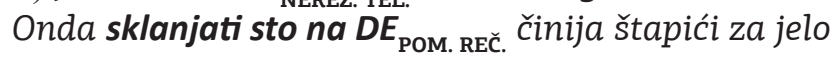

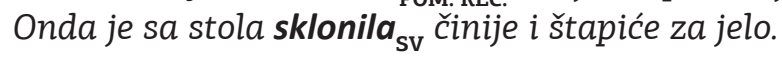

(He, 1997: 320)

U datom primeru, objekat WAN KUAI/činija i štapići za jelo specifikovan je odrednicom ZHUO SHANG DE/ono što je na stolu, što čini radnju koju opisuje nerezultativni telični glagol SHOUSHI/sklanjati ograničenom.

\subsubsection{Diskursna sredstva}

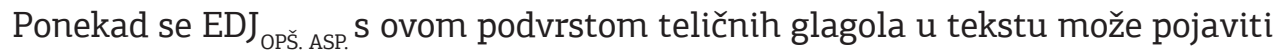
u određenim glagolskim konstelacijama i ograničenu situaciju izraziti tako što će i sa susednom ili susednim klauzama formirati niz događaja u temporalnoj sukcesiji. U takvim slučajevima, samo se spoljašnja krajnja tačka te ograničene situacije (bilo da je temporalna ili materijalna) označava jezičkim iskazima koji se nalaze u narednoj klauzi ili u većem tekstualnom spanu. Pogledajmo sledeće primere: 
8) Wuduo... bei Daniang jiejieshishi da-le yi kuaizitou, cai mang-zhe chi ${ }_{\text {NEREZ. TEL. }}$ fan, shou $_{\text {NEREZ. TEL. }}$ wan, $\boldsymbol{x i}_{\text {NEREZ. TEL. }}$ guOZi.

Vuduo...BEI $I_{\text {PRED. ZA PASIV. }}$ gazdarica snažno udarati-LE $E_{\text {ASP. MAR. }}$ jedan štapići za jelo glava, tek žuriti-ZHE ${ }_{\text {ASP. MAR. }}$ ručati, skupljati činija pratiti tiganj

Tek kad ju je gazdarica snažno udarila štapićem po glavi, požurila je s jelom, pokupila $_{\mathrm{sv}}$ činije i oprala sv $_{\text {tiganj. }}$

(Шен, 2014: 166)

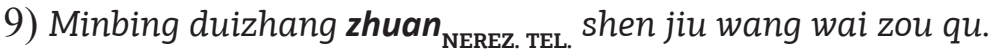

Civilna milicija komamdir okretati se telo ka spolja ići otići

Komandir milicije se okrenuo sv uputio ka izlazu.

(Mo, 2015: 266)

Primer (8) predstavlja događajni niz iskazan glagolskom konstelacijom od kojih su CHI (FAN)/ručati, SHOU/skupljati, XI/prati nerezultativni telični glagoli. Budući da se ovaj događajni niz nalazi na glavnom toku priče u kojem se ostvaruje temporalna progresija, ove radnje predstavljaju ograničene sukcesivne događaje. U primeru (9), nerezultativni telični glagol ZHUAN (SHEN)/okretati se i rezultativni glagol LIKAI/napustiti, napuštati čine dve korefencijalne podradnje sumirajućeg odnosa, koje su temporalno sukcesivne, te je radnja koju opisuje nerezultativni telični glagol interpretirana kao ograničena.

\subsubsection{Druga jezička sredstva}

Jedno od čestih jezičkih sredstava kojima se ostvaruje ograničenost kod EDJ ${ }_{\text {OPšs. }}$ ASP. S nerezultativnim teličnim glagolima je dodavanje modalne rečce $L E$ sa značenjem ostvarenja na kraj EDJ, što je ilustrovano sledećim primerima:

10) Jixingzi de ren tuo-le xie, zhan zai yizi shang $q u_{\text {NEREZ.TEL }}$ xingli le.

Nestrpljiv $D E_{\text {POM. REČ. }}$ čovek skinuti-LE $E_{\text {ASP. MAR. }}$ cipele, ustati na stolica gore uzimati prtljag $L E_{\text {MOD. REČ. }}$

Neki nestrpljivi čovek skinu cipele i pope se na sedište da dohvati ${ }_{\mathrm{sv}}$ prtljag.

(Ванг, 2015: 17)

11) Youren bang-zhe xunzhao ${ }_{\text {NEREZ.TEL. }}$ Ma Erli le,...

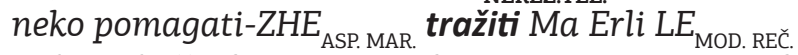

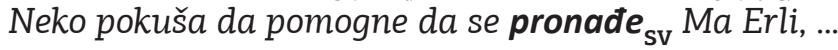

U gorenavedenim primerima, na kraju klauze dodata je modalna rečca LE koja u kineskom jeziku ima razne gramatičke funkcije, kao što su označavanje ostvarenja određene situacije, promene stanja i druge. Ovde ona označava da su radnje $Q U$ XINGLI/uzimati prtljag (primer 10) i XUNZHAO Ma Erli/tražiti Ma Erlija (primer 11) ostvarene. Drugim rečima, ove radnje koje opisuju nerezultativni telični glagoli jesu 
početnosvršene, iako potencijalni rezultati u datom trenutku još nisu postignuti. Ovo značenje u srpskom prevodu prikazano je namernom klauzom koja se uvodi veznikom da. U korpusu se sreću i taksisni specifikatori, kao što su YI...(JIU).../čim... (odmah)..., BIAN/i (odmah), JIEZHE/zatim i drugi, pomoću kojih ove EDJ sa susednom klauzom formiraju temporalni sukcesivni niz, pri čemu dobijaju značenje ograničenosti.

$\mathrm{Na}$ osnovu gorenavedenog, smatramo da EDJ $\mathrm{OPŠ.} \mathrm{ASP.}_{\mathrm{s}} \mathrm{s}$ nerezultativnim teličnim glagolima mogu uslovljeno opisati ograničenu situaciju u narativnom diskursu, i to uz pomoć leksičkih, gramatičkih ili diskursnih sredstava.

4.2.2. Načini izražavanja ograničenosti rezultativni glagola opšteg aspekta

U odnosu na nerezultativne, rezultativni telični glagoli, s inherentim i ostvarenim ciljem glagolskog procesa, pokazuju veću samostalnost u realizaciji ograničenosti na nivou klauze. Takođe smo zapazili da radnje koje opisuju takve EDJ u temporalnoj strukturi narativnog diskursa često služe kao uočljiva vremenska referenca za počinjanje naredne radnje, bilo da su one u rečeničnoj konstelaciji ili u vremenskoj zavisnoj klauzi. Štaviše, one češće čine poslednji događaj u nekom događajnom nizu, pri čemu svojom inherentnom krajnom tačkom okončavaju celo zbivanje. Pogledajmo sledeći primer:

12) Jiezhe jiu fan-xialai shi kuang pingguo, xiamian san ge ren ba kuanggai xian-kai wang tamen ziji de kuang li dao $_{\mathrm{REZ} . \mathrm{TEL}}$.

Zatim onda obarati-ići dole deset košara jabuka, dole tri KLAS. za osobe čovek $B A_{\text {PRED. }}$ poklopac skidati-otvoriti ka oni svoj DE $E_{\text {POM. REČ. }}$ kotarica unutra (pre)sipati

Zgrabili desetak košara ... Ovi su ih spremno dočekivali, cepali poklopac i presipali $i_{\text {sv }}$ jabuke u sopstvene kotarice.

(Jy, 2015: 115)

13) Ta jimang cong kang shang pa-qilai, xia $_{\text {REz. TEL. }}$ kang shi huhututu di zai-daole di shang.

Ona užurbano iz kang/krevet gore ustajati-uzdići, sići/silaziti kang/krevet kada zbunjen $D E_{\text {POM. REČ. }}$ sapletati-pasti-LE $E_{\text {ASP. MAR. }}$ pod gore

Užurbano se pridigla, i tako zbunjena se, silazeći ${ }_{\text {NSv. GER. }}$ s kanga, saplela i pala na pod.

(Mo, 2015: 268)

U primeru (12), događajni niz opisuju tri vremenski sukcesivne rečenice ili klauze, među kojima prve dve klauze pomoću rezultativnih dopuna XIALAI/ići dole i $\mathrm{KAI} /$ otvoriti ostvaruju ograničenost. Rezultativni glagol DAO/(pre)sipati, koji se nalazi u poslednjoj klauzi, svojim ostvarenim rezultatom okončava celo dešavanje, i to bez sadejstva aspekatskih markera i modalne rečce $L E$ za ostvarenje ili promenu stanja. Na taj način se klauza tumači kao perfektivna. U primeru (13), rezultativni glagol XIA (KANG)/sići, silaziti (s kreveta) nalazi se u vremenskoj subordiniranoj klauzi (...SHI/kada...), čineći narednoj radnji ZAI-DAO/saplesti referentno vreme, što je 
prevedeno oblikom nesvršenog gerunda na srpski jezik, sa značenjem simultanosti dve radnje.

Pored gorepomenutog, rezultativni glagoli, kao i oni telični, a nerezultativni, mogu da se nalaze u glagolskoj konstelaciji i da sa susednim perfektivnim EDJ čine niz sukcesivnih radnji ili koreferencijalnu radnju tipa sumiranja, pri čemu se ostvaruje ograničenost EDJ.

Treba pomenuti i da narativni diskurs nama omogućava da odredimo da li ovi rezultativni glagoli opisuju dinamičnu radnju ili, pak, statično stanje, kao rezultat postignut izvršenjem radnje. Upravo zbog ove dvostruke osobine, EDJ ${ }_{\text {OPŠ. ASP. }}$ s rezultativnim glagolima neretko (oko 48,47\% od ukupnih) mogu u određenom kontekstu da se tumače i neograničenim situacijama. Na kraju, smatramo da ove EDJ ${ }_{\text {OPš. ASP. }}$ predstavljaju nemarkirane jezičke izraze za izražavanje aspekatskog značenja u kineskom jeziku, a da pritom nisu „aspekatsko markirani“, kako Jang tvrdi, „samo što su im aspekatski markeri izostavljeni iz diskursnih razloga, jer uz događaje koji prethode poslednjem, može stajati perfektivni marker ukoliko ih govornik posmatra kao zasebni događaj“ (Yang, 1995: 139). Ipak, kod gorenavedenih primera, perfektivni marker LE nije mogao da se proizvoljno doda u bilo koju EDJ ${ }_{\text {OPŠ. ASP. }}$ Recimo, teličnom glagolu u primeru (8) ne može se dodati marker LE jer se on nalazi u glagolskoj konstelaciji, odnosno u tzv. „rečenici neprekidnog toka“ (LIUSHUIJU), pa bi dodavanjem markera $L E$ došlo do prekida toka pripovedanja u ovom diskursnom spanu.

\section{Prevodni ekvivalenti u srpskom jeziku}

Nakon kvantitativne analize srpskih prevodnih ekvivalenata teličnih glagola u TP strukturi narativnog diskursa, dobili smo zanimljive podatke koji su prezentovani u Tabeli 4. U koloni označenoj „ostalo“ prikazani su brojevi EDJ ${ }_{\text {OPš. AsP. }}$ obe podvrste teličnih glagola koje nisu prevedene klauzama s glagolskim predikatom, već su na srpskom jeziku izražene pridevskim ili imeničkim frazama, ili, prosto, neprevedene slobodnim izborom prevodilaca.

\begin{tabular}{|c|c|c|c|c|c|c|}
\hline \multirow{2}{*}{ Tip gl. } & \multirow{2}{*}{$\begin{array}{l}\text { br. } \\
\text { EDJ }\end{array}$} & \multicolumn{2}{|c|}{ SV } & \multicolumn{2}{|c|}{ NSV } & \multirow{2}{*}{ estalo } \\
\hline & & PERF & AOR & $\begin{array}{l}\text { PERF u upr } \\
\text { klauzama }\end{array}$ & $\begin{array}{l}\text { NSV u zax, } \\
\text { klauzama }\end{array}$ & \\
\hline \multirow{3}{*}{ NEREZ. TEL. Gl. } & \multirow{3}{*}{175} & 107 & 26 & 13 & 19 & 10 \\
\hline & & \multicolumn{2}{|c|}{133} & \multicolumn{2}{|c|}{32} & \\
\hline & & & & \multicolumn{2}{|c|}{$18,29 \%$} & $5,71 \%$ \\
\hline \multirow{3}{*}{ REZ. TEL. Gl. } & \multirow{3}{*}{135} & 97 & 12 & 8 & 3 & 15 \\
\hline & & \multirow{2}{*}{\multicolumn{2}{|c|}{109}} & \multirow{2}{*}{\multicolumn{2}{|c|}{11}} & \\
\hline & & & & & & $11,1 \%$ \\
\hline
\end{tabular}

Tabela 4. Distribucija vidskih glagolskih oblika u prevodu [Sr] teličnih glagola u TP EDJ $_{\text {OPŠ. ASP. }}[\mathrm{Kin}] \mathrm{u}$ analiziranom korpusu

5.1. Prevodni ekvivalenti u srpskom jeziku nerezultativnih teličnih glagola opšteg aspekta

Prema podacima u gorenavedenoj tabeli, od ukupno 165 TP EDJ OPŠ. AsP. $_{\text {s ovom }}$ podgrupom teličnih glagola, koje su prevedene klauzama s glagolskim predikatom, 
76\% EDJ je prevedeno svršenim preteritom; a 18,29\% EDJ nesvršenom predikacijom (uključujući nelične glagole nesvršenog vida). Svršeni glagolski oblik u preteritu izražava kompletivne i ograničene događaje u prošlosti, pa je zato on i najčešće korišćeni glagolski oblik u narativu srpskog jezika. Prema našim podacima, pripovedački aorist se manje upotrebljava od pripovedačkog perfekta u temporalnoj strukturi narativa za iskazivanje ograničene predikatske situacije. EDJ s nesvršenim glagolima, bilo da je reč o ličnom ili neličnom obliku, obično opisuju radnje čiji se ciljevi još nisu ostvarili (vidi primer 1a) ili mnoštvo radnji, što je ilustrovano sledećim primerima:

14) Zhishi wuxian lian'ai de shuli ${ }_{\text {NEREZ. TEL. }}$ ta shenshang de mao, yi bian you yi bian de, ...

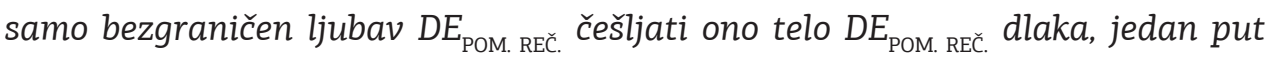
opet jedan put $D E_{\text {POM. REČ. }}$

...samo mu je s bezgraničnom ljubavlju češljala ${ }_{\mathrm{Nsv}}$ dlaku, jednom, pa još jednom.

(He, 1997: 320)

15) Cunzhang yidazao ba Peng Dabu cong beiwo li jiu-chulai, ma $a_{\text {NEREZ. TEL. }}$ ta: ... Starešina sela rano jutro $B A_{\text {PRED. }}$. Peng Dabu iz postelja vući-izaći $i_{\text {REZ. DOP. }}$ psovati on U rano jutro starešina sela je izvukao Krakatog Penga iz postelje psujući ${ }_{\text {Nsv }}$...

(Чи, 2014: 67)

U primeru (14), budući da se u EDJ nalazi adverbijal koji opisuje mnoštvo radnji YI BIAN YOU YI BIAN/jednom, pa još jednom, nerezultativni telični glagol SHULI/češljati preveden je glagolom nesvršenog oblika. U primeru (15), prevodni ekvivalent nerezultativnog teličnog glagola $\mathrm{MA} /$ psovati jeste u obliku nesvršenog gerunda koji označava taksisni odnos simultanosti između dve radnje u datoj rečenici. Budući da se radi o glagolu govorenja, cilj ove radnje ostvaruje se tek nakon okončanja govornog čina, čime se zatvara desna granica situacije.

Od perfektivnih glagola $u$ analiziranom korpusu, najviše ima onih koji imaju specifične leksičke prefikse, tj. prema Beliću (Белић, 1998) „sekundarnih“ perfektivnih, a prema Piperu i Klajnu (Пипер/Клајн, 2013), akcionalno modifikovanih glagola, kao što su: po-: pokupiti/SHOUSHI, počistiti/SHOUSHI, poviknuti/HAN, pokazati/ZHI, pozvati/JIAO; za-: zasnovati (porodicu)/CHENG (JIA), zapaliti/DIAN; iz(s)-: ispričati/SHUO, izvući se/LIU; do-: dodati/SHUO, SHENGCHENG, dohvatiti/MO; pro-: promumlati/DUNANG; od-: odavati/GEI; s(a)-: savladati/KEFU; $u$-: upitati/WEN, itd. Činjenica je da u srpskom jeziku postoji posebna grupa glagolskih prefiksa (od kojih je trinaest najproduktivnijih) ${ }^{14}$ koji imaju veliku tvorbenu moć u obrazovanju perfektivnih složenih glagola i koji igraju važnu ulogu u određivanju spoljašnje granice (završne tačke) procesa. Stoga se granično-kvantitativno značenje može smatrati njihovim bitnim semantičkim obeležjem. Što se prevodnih ekvivalenata u nesvrše- 
nom obliku tiče, oni koji se često sreću u analiziranom korpusu jesu imperfektizovani prefiksalni glagoli, tj. „sekundarni imperfektivi“, kao što su: zadržavati/LIU, ispunjavati/PU (BI), itd. Funkcije ovih imperfektizovanih glagola u narativnom diskursu, po nama, jesu neutralisanje rezultativnosti nekog procesa, kao i isticanje segmenta ograničene trajnosti koji prethodi cilju tog procesa.

U srpskoj literaturi, ovu podgrupu teličnih glagola Grubor (Гpyбop, 1953: 41) naziva verba caeca, odnosno „slepim glagolima“. Govoreći o osobinama ovih glagola, Grubor tvrdi da njihova „izvršenost zavisi od stvari prikrivenih ili kojih možda i nema, a subjekat to ne zna“. Navodeći pritom i primere: loviti-uloviti, moliti-izmoliti, hvatati-uhvatiti, on dalje ističe da se ova grupa glagola, pak, razlikuje od pantivnih ili totivnih jer izvršena radnja ne mora biti i uspešna, odnosno, ona može biti i bez rezultata. O tome je Grickat (1966/67: 200) imala drugačije mišljenje. Ona, između ostalog, ističe da: „kod glagola tipa gađati, moliti, tražiti njihova eventualna kompleksivnost nije u činjenici pogotka ili dobijanja; toga može i biti i ne biti. Pogodak ili dobijanje, tj. uspeh, jeste spoljni faktor." Uspešnost ili posledice ovih radnji ona naziva „vanglagolskom rezultativnošću“. Po pitanju ovih „slepih glagola“, iz ugla ovog istraživanja gledano, slažemo se s mišljenjem Grickat da glagoli tipa pogađati, uhvatiti, nisu gramatički parnjaci glagolima tipa gađati, hvatati, jer su temporalne strukture procesa ovih dvaju tipova glagola različite, zbog čega oni zapravo pripadaju različitim podgrupama teličnih glagola ${ }^{15}$. Tačnije, glagoli tipa gađati, hvatati su nerezultativno-telični, dok su glagoli tipa pogađati, uhvatiti, uloviti, izmoliti, itd., rezultativni.

\subsection{Prevodni ekvivalenti rezultativnih glagola opšteg aspekta}

Na osnovu podataka prikazanih u Tabeli 4, uočeno je da od onih koje su prevedene klauzama s glagolskim predikatom, oko 80,74\% ovih EDJ prevedeno je svršenim perfektom ili aoristom. Iako su ove EDJ ređe prevođene nesvršenim vidom, naišli smo, doduše, i na po koji primer s gerundivnom konstrukcijom koja izražava radnju na glavnoj niti priče (vidi primer 13).

Među prevodnim ekvivalentima javljaju se dva tipa glagola. Prvi čine oni koji imaju gramatičke vidske parnjake, kao što su: ući-ulaziti/JIN, stići-stizati/XIA, vratiti se-vraćati se/HUI, nestati-nestajati/XIAOSHI, početi-počinjati/KAISHI, rešiti-rešavati/JIEJUE, videti/JIAN i dr., a drugi čine glagoli sa prefiksima, kao što su: odgovoriti/ HUIDA, osvrnuti se/HUI (TOU), ustati/QI (SHEN), pridobiti/DEDAO i dr. U tekstualnim spanovima u kojima temporalne progresije nema, rezultativni glagoli kineskog jezika se prevode nesvršenim glagolima, i to su: viđati/KAN, vraćati se/HUI, dobijati/ DE, stizati/DAO, počinjati/KAISHI, što su glagoli prvog tipa, ali i izgovarati/HUIDA, izlaziti/CHU, odlaziti/LAI, iščezavati/XIAOSHI, odbijati/JUJUE, koji spadaju u glagole drugog tipa. Značenja i funkcije ovih imperfektivnih teličnih glagola u netemporalnoj strukturi diskursa jesu neutralisanje rezultativnosti, isticanje segmenta trajanja - „perioda pripreme“ za ostvarivanje cilja, ili izražavanje nereferencijalnih radnji, kao i opisivanje stanja, tj. trajanja uticaja određene svršene radnje. 
Takođe je evidentirano i da je mali broj rezultativnih glagola u netemporalnoj strukturi diskursa preveden na srpski svršenim glagolima pasivnog oblika, kojima se izražava trajanje efekta (uticaja) ostvarenog rezultata radnje, kao što su: (rajsferšlus) iskrzan/BAI (CHI), izgubljena/SHIQU, osvetljen/BEI DENGGUANG LONGZHAO i drugi. Ima i onih koji su prevedeni prilozima ili imeničkim frazama kojima se imenuju rezultati ili stanja.

\section{Zaključak}

Telični glagoli razlikuju se po tome da li u svom imanentnom semantičkom značenju poseduju semu [rezultat] ili ne. Kroz kineski jezik kao prizmu, pokazalo se da se u narativnom diskursu ipak može utvrditi (ne)ograničenost rečenica ili klauza čije predikate čine samo telični glagoli, uključujući i rezultativne glagole. Empirijskom i kvantitativnom analizom dokazano je da oni telični glagoli koji nisu rezultativni, kao i oni koji to jesu, imaju različite sintaksičke osobine i nemaju isti potencijal za izražavanje ograničene situacije. Tačnije, u narativnom diskursu nerezultativni telični glagoli opšteg aspekta pokazuju veću tendenciju da izražavaju ograničenost $u$ odnosu na rezultativne, ali su po tom pitanju zavisni od određenih sintaksičkih i diskursnih uslova (kao što su kvantifikacija glagolskog objekta, upotreba modalne rečce $L E$ za promenu stanja ili ostvarenje, ili nalaženje u događajnom nizu, itd.), dok rezultativni glagoli opšteg aspekta deluju mnogo samostalnije u izražavanju ograničene situacije, ali ne pokazuju posebnu tendenciju pojavljivanja u ograničenoj, odnosno, neograničenoj situaciji. Ove EDJ ${ }_{\text {OPš. AsP. }}$ u kineskom jeziku, po nama, predstavljaju nemarkirane jezičke izraze za izražavanje aspektualnosti.

Poređenjem teličnih glagola u kineskom originalu s njihovim prevodnim ekvivalentima u srpskom jeziku pokazuje se da je aspekatska vrednost kineskih teličnih glagola u ograničenim EDJ prikazana i perfektivnim i imperfektivnim glagolskim oblicima u srpskom jeziku, što znači da se ne može staviti znak jednakosti između gramatičke aspekatske opozicije „perfektivnost-imperfektivnost“ u srpskom jeziku i opozicije ograničenost-neograničenost u kineskom jeziku. Međutim, potvrđeno je da se kineski telični glagoli u ograničenoj situaciji najviše prevode svršenim glagolima u srpskom jeziku. Pored toga, kada je srpski jezik u pitanju, jedno od glavnih sredstava za realizaciju cilja radnje jeste perfektivizacija glagola pomoću prefiksacije na morfološko-tvorbenom nivou, što je jedan od glavnih razloga zašto u srpskom jeziku postoji vidljivo veći broj rezultativnih glagola u odnosu na kineski jezik. Bilo bi poželjno da se u budućnosti sprovedu detaljna istraživanja o načinima izražavanja ovih srpskih rezultativnih glagola na kineskom jeziku, što će sigurno u velikoj meri doprineti produbljivanju kontrastivnih istraživanja ova dva jezika.

Napomena: Rad je dorađeni deo autorkine neobjavljene doktorske disertacije Aspekt i temporalna progresija u narativnom diskursu, koja je odbranjena 15. 06. 2020. na Filološkom fakultetu u Beogradu. 


\section{Literatura}

Carlson, L., Marcu, D. (2001). Discourse Tagging Reference Manual, ISI Tech Report ISITR-545. RST Corpora, Tools, and Software. http://www.isi.edu/ marcu/discourse

Chu, C. (1987). The semantics, syntax, and pragmatics of the verbal suffix Zhe. Journal of the Chinese Language Teachers Association, 22(1), 1-41.

Comrie, B. (1976). Aspect: An Introduction to the Study of Verbal Aspect and Related Problems. Cambridge: Cambridge University Press.

Declerck, R. (1989). Boundedness and the Structure of Situations. Leuvense Bijdragen, 78, 275-308.

Declerck, R. (2007). Distinguishing between the aspectual categories '(a)telic', '(im) perfective' and '(non)bounded'. Kansas Working Papers in Linguistics, 29, 48-64.

Dowty, D. (1979). Word Meaning and Montague Grammar. Dordercht: D. Reidel Publishing Company.

Hopper, P. (1979). Aspect and Foregrounding in Discourse. Discourse and Syntax, 12, 211-241.

Hopper, P. (1982). Aspect between Discourse and Grammar: An Introductory Essay for the Volume. In P. Hopper (Ed.), Tense-Aspect: Between Semantics and Pragmatics (pp. 3-18). Amsterdam: John Benjamins.

Kamp, H., Rayle, U. (1993). From Discourse to Logic. Kluwer: Dordrecht.

Li, C. N., Thompson, S. A. (1981). Mandarin Chinese: A Functional Reference Grammar. Berkeley: University of California Press.

Lindstedt, J. (1995). Understanding perfectivity-understanding bounds. In P. Bertinetto,

V. Bianchi, O. Dahl, M. Squartini (Eds.), Temporal Reference, Aspect and Actionality (pp. 239-247). Torino: Rosenberg \& Sellier.

Mann, W., Thompson, S. (1988). Rhetorical Structure Theory: Toward a Functional Theory of Text Organization. Text \& Talk, 8(3), 243-281.

Meng, C., deng (bian). (1999). Hanyu dongci yongfa cidian. Beijing: Shangwu yinshuguan. Novakov, P. (2005). Glagolski vid i tip glagolske situacije u engleskom i srpskom jeziku. Novi Sad: Futura publikacije.

Shen, J. (1995). "Youjie" yu "wujie”. Zhongguo yuwen, di 5 qi (zong di 428 qi), 367-380.

Shen, J. (2004). Zai tan "youjie" yu "wujie". Yuyanxue luncong, di 30 ji, 40-54.

Smith, C. (1991/1997). The parameter of aspect. Dordrecht: Kluwer.

Vendler, Z. (1967). Verbs and Times. In Linguistics in Philosophy (pp. 97-121). Ithaca, NY: Cornell University Press.

Wang, L. (1943/1985). Zhongguo xiandai yufa. Beijing: Shangwu yinshuguan.

Xiao, R., McEnery, T. (2004). Aspect in Mandarin Chinese: a corpus-based study. Amsterdam: John Benjamins Publishing Co.

Yahongtuofu, S. (1958). Hanyu de dongci fanchou (K. L. Chen, yi). Beijing: Zhonghua shuju.

Yang, S. (1995). The Aspectual System of Chinese (unpublished doctoral dissertation). University of Victoria, Ontario.

Yang, S., Huang, Y., Wang, Y. (2009). Hanyu qingzhuang fenlei ji fenlei zhong de wenti. Yuyanxue luncong, di 39 ji, 478-505. 
Jin, X. S. 2019. Aspekt i temporalna progresija u narativnom diskursu (neobjavljena doktorska disertacija). Filološki fakultet, Univerzitet u Beogradu.

Zhang, X. (1957). Hanyu dongci de "ti" he "shizhi" xitong. Yufa lunji, di I ji, 154-174.

Белић, А. (1998). Системи стварних глаголских значења. У М. Ивић (прир.), Општа мингвистика (први том): О језичкој природи и језичком развитку. Кюига I и II (стр. 255-266). Нови Сад: Будућност.

[Belić, A. (1998). Sistemi stvarnih glagolskih značenja. U M. Ivić (prir.), Opšta lingvistika (prvi tom): O jezičkoj prirodi i jezičkom razvitku. Knjiga I i II (str. 255-266). Novi Sad: Budućnost]

Грицкат, И. (1966/67). Префиксација као средство граматичке (чисте) перфектизације. Јужнословенски филолог, XXVII(1-2), 185-224.

[Grickat, I. (1966/67). Prefiksacija kao sredstvo gramatičke (čiste) perfektizacije. Južnoslovenski filolog, XXVII(1-2), 185-224]

Грубор, Ђ. (1953). Аспектна значеюа. Загреб: Југославенска академија знаности и умјетности.

[Grubor, Đ. (1953). Aspektna značenja. Zagreb: Jugoslavenska akademija znanosti i umjetnosti]

Клајн, И. (2003). Творба речи у савременом српском језику. Други део. Београд: Завод за уџбенике и наставна средства.

[Klajn, I. (2003). Tvorba reči u savremenom srpskom jeziku. Drugi deo. Beograd: Zavod za udžbenike i nastavna sredstva]

Пипер, П., Клајн, И. (2013). Нормативна граматика српског језика. Нови Сад: Матица српска.

[Piper, P., Klajn, I. (2013). Normativna gramatika srpskog jezika. Novi Sad: Matica srpska]

\section{Izvori}

Ванг, А. (2015). Последња станица воза (И. Елезовић, прев.). У у првом мицу: Антологија савремене кинеске приче (стр. 17-47). Београд: Геопоетика.

[Vang, A. (2015). Poslednja stanica voza (I. Elezović, prev.). U U prvom licu: Antologija savremene kineske priče (str. 17-47). Beograd: Geopoetika]

Ју, Х. (2015). Далеко од куће у осамнаестој (3. Скробановић, прев.). У У првом мииу: Антологија савремене кинеске приче (стр. 110-118). Београд: Геопоетика.

[Ju, H. (2015). Daleko od kuće u osamnaestoj (Z. Skrobanović, prev.). U U prvom licu: Antologija savremene kineske priče (str. 110-118). Beograd: Geopoetika]

Лу, В. (2015). Зид (М. Павловић, прев.). У У првом ^ииу: Антологија савремене кинеске приче (стр. 66-90). Београд: Геопоетика.

[Lu, V. (2015). Zid (M. Pavlović, prev.). U U prvom licu:Antologija savremene kineske priče (str. 66-90). Beograd: Geopoetika]

Мо, Ј. (2015). Синовљев непријатељ (А. Јовановић, прев.). У У првом ^ииу: Антологија савремене кинеске приче (стр. 247-268). Београд: Геопоетика.

[Mo, J. (2015). Sinovljev neprijatelj (A. Jovanović, prev.). U U prvom licu: Antologija savremene kineske priče (str. 247-268). Beograd: Geopoetika] 
Сун, Л. (2014). Савет на растанку (Т. Бокић, прев.). Београдски књижевни часопис, 36-37, 68-76.

[Sun, L. (2014). Savet na rastanku (T. Bokić, prev.). Beogradski književni časopis, 36-37, 68-76]

Хе, Б. (1997). Имали смо госта (Р. Пушић, прев.). Мостови, 110, 315-320.

[He, B. (1997). Imali smo gosta (R. Pušić, prev.). Mostovi, 110, 315-320]

Чи, Ц. (2014). Трампа (У. Мишковић, прев.). Београдски кюижевни часопис, 36-37, 52-67.

[Či, C. (2014). Trampa (U. Mišković, prev.). Beogradski književni časopis, 36-37, 52-67]

Шен, Ц. (2014). Муж (М. Павловић, прев.). У Антологија модерне кинеске приче (стр. 150-173). Београд: Геопоетика.

[Šen, C. (2014). Muž (M. Pavlović, prev.). U Antologija moderne kineske priče (str. 150173). Beograd: Geopoetika]

\section{Xiaolei S. Jin}

\section{Summary}

\section{TELIC VERBS AND BOUNDED SITUATION IN CHINESE}

Based on the results of corpus analysis, this paper examines Chinese telic and resultative verbs, and their relationships with "bounded" situations. Guided by empirical and quantitative analysis, its purpose is to shed some light on the distribution of these telic verbs in narrative discourse, as well as their possibilities and ways of expressing "boundedness" without the help of other aspect operators. The results of our research show the necessity to further classify this verb class into non-resultative and resultative telic verbs, since there are significant differences between them in syntactic and discourse behavior in expressing "boundedness". Finally, a contrastive analysis of these verbs in the Chinese original and their translation equivalents in the Serbian language reveals the main ways in which the Serbian language renders the meanings of "boundedness" and "resultative" features of Chinese telic verbs.

\section{Key words:}

telicity, boundedness, resultativity, verbs, Chinese, Serbian 